\title{
Trazos, conexiones, constelaciones: Diez de Juan Emar y Brígida o el olvido de Rosamel del Valle
}

\author{
Lines, connections, constellations: Diez by Juan Emar \\ and Brígida o el olvido by Rosamel del Valle
}

\section{Rodrigo GonZÁlez DinAMARCA}

Pontificia Universidad Católica de Chile. Santiago, Chile

rigonza2@uc.cl

\section{RESUMEN}

Este trabajo se propone analizar el motivo de la aparición de constelaciones -conexiones entre elementos que dan lugar a figuras- en la obra Diez de Juan Emar y Brígida o el olvido de Rosamel del Valle, en la medida que cumplen un papel decisivo en la búsqueda de una realidad otra. El primer elemento del análisis es la línea en la representación del destino humano y la conexión con la otra realidad. Posteriormente, se observa de qué forma se construyen figuras o constelaciones en las obras mencionadas, y cómo se relaciona con el sentido de búsqueda de una realidad otra.

Palabras clave: Figuras, líneas, intersticios, triángulos.

\section{ABSTRACT}

This paper analizes the topic of the appearance of constellations -connections between elements that generate figures- in the work Diez by Juan Emar and in Brígida o el olvido written by Rosamel del Valle, where these figures represent a decisive role in the search of another reality. The first element to be analized is the line in the representation of the human destiny and in the connection with another reality. After 
that, there is observed the form in that the figures or constellations are built in these works, and how it refers to the search of an alternative reality.

Keywords: Figures, lines, interstices, triangles.

Recibido: 13.03.2012. Aceptado: 02.08.2012.

\section{LA APARICIÓN DE UNA NUEVA REALIDAD}

Crente a la imposibilidad de encontrar la Verdad del hombre mediante - la razón científica de raíz ilustrada, se genera, en el romanticismo, una sensación de descontento y comienza la búsqueda de nuevas vías para llegar a esa Verdad, basadas en lo subjetivo. El surrealismo es, primeramente, una nueva forma de ese descontento respecto a las formas de comprensión de la vida y del hombre avaladas por la conciencia científica y la lógica racional. Se vierte también hacia las zonas más inexploradas de la interioridad humana, a fin de dar una visión global de la vida, en que se integre el estado de vigilia con el mundo onírico en una superrealidad.

Esta crisis, como señala Cirlot (1953), tiene lugar en un contexto caracterizado por el desmoronamiento de los valores fundamentales de la cultura occidental y por el desgarro de "la unidad en que el ser humano vivía sumido, mostrándole dimensiones a las que no tiene acceso, o que, simplemente, existen sin ofrecérsele" (23). Asimismo, señala Hatzfeld (1951) que el mundo se presenta fragmentado, y la reacción del artista es la de "reunir en nuevas asociaciones las disociaciones de una unidad que ya no se ve" (14). La dinámica consiste en que el surrealismo reintegra lo que el realismo ha desintegrado (15). En la literatura surrealista, que se aboca a la tarea de descubrir las "ocultas verdades de la vida" (17), se anulan las convenciones y se transgreden los límites de la conciencia para que el autor se exprese sin restricciones. Desaparecen "los frenos de la vergüenza" (17) para dar cabida a una verdadera expresión que indaga en los terrenos más profundos del mundo interior del artista.

De esta forma es coherente pensar en los cuentos de Diez de Juan Emar (2006) o en la novela Brígida o el olvido de Rosamel del Valle (2009) como muestras patentes de literatura surrealista. Este trabajo se propone comprender a ambos autores como manifestantes de una inquietud vital, como exploradores en una nueva zona de realidad; en fin, como escritores cuya pluma está abocada a realizar una fuga desde la realidad concreta, tan evidente como insuficiente, hacia otros sitios caracterizados por la ruptura de 
los moldes lógicos o de lo aparente y funcional.

Así pues, disconformes con la realidad inmediata, ambos autores dirigen su atención hacia otra realidad. Aquí comienzan a asomarse algunas luces sobre la experiencia humana, a la vez que se pretende encontrar un refugio o vía de escape del mundo. A pesar de que Hatzfeld señala que el surrealismo no pretende evadir la realidad, como el romanticismo, sino que descubrirla (1951: 8), hay, a mi parecer, una innegable intención de evasión en la búsqueda de esa verdad. La disconformidad, que se traduce en una desmesurada ansia de fuga, se caracteriza tanto en Emar como en Rosamel por un rechazo a la mediocridad de la vida burguesa.

Es así como podemos encontrar en ambos autores la recurrencia a ciertas imágenes en común para referirse al tema del destino humano y a su conexión con la realidad otra, que constituye una alternativa fuera del mundo tangible que resulta tan insatisfactorio. En primer lugar, aparece la imagen de la línea. A partir de las líneas se establecen conexiones entre los elementos de la realidad, formando figuras entre ellas. Tanto la línea en sí misma como las figuras que surgen de la aplicación de ésta en la conexión de elementos son fundamentales en la representación del destino humano y de la otra realidad. Cabe ahora plantearse algunas preguntas: ¿Cómo actúan las líneas y constelaciones en dichas representaciones? ¿Qué sentido aportan en la exploración de la otra realidad? ¿Qué tienen en común estas representaciones en los cuentos de Juan Emar y en la novela Brígida o el olvido de Rosamel del Valle?

Mary Mac-Millan, en El intersticio como fundamento poético en la obra de Julio Cortázar (2005), plantea que en la escritura de dicho autor la otra realidad se manifiesta en un instante, en una suerte de "chispazo" surrealista en el que se logra entrever la otra realidad a través del intersticio, concepto que se entiende como "una determinada articulación de elementos de la realidad que favorecen una entre-visión de una realidad otra" (47). El descubrimiento de ese mundo velado se da por un quiebre instantáneo del continuum (43) que permite el surgimiento de constelaciones. Este mecanismo es evidenciado por Soledad Traverso (1999) en la obra de Juan Emar, ya que se busca "interrumpir la realidad del continuum y producir el vacío que lo llevará a percibir la otra realidad, donde todo cobra sentido" (81). Algo similar puede decirse sobre Brígida o el olvido, donde el continuum de la realidad tangible es constantemente fracturado cuando el protagonista se desdobla hacia su realidad interior.

La experiencia intersticial consiste en una apertura instantánea que permite entrever otra realidad y conlleva una suspensión o "dejar de ser" (2005: 
42) en que las cosas se muestran de manera diferente. Mac-Millan señala que el espacio intersticial se genera por "figuras o constelaciones" (53). En Emar y Rosamel es posible encontrar estas figuras que consisten, ante todo, en la unión de los fragmentos en una sola unidad. Sin embargo, como se verá, estas constelaciones cumplen una función distinta en cada uno de los autores: mientras que en Emar la figura aparece ante él para llevarlo hacia la otra realidad, en Rosamel aparece cuando ya se está en la otra realidad, como una manera de mantenerla en el tiempo y resistir al olvido, motivo fundamental de Brígida.

Es fundamental entender el carácter sumamente frágil e instantáneo de la constelación: en algún momento la realidad recobrará al individuo para sí. El protagonista de Brígida es continuamente aterrizado desde su ensoñación al mundo ordinario cuando, por ejemplo, otro personaje dice algo, o cuando tropieza con alguien en la calle. La realidad -el continuum- se le impone, y lo saca de la lluvia de imágenes del recuerdo -prefiguración inconexa, potencial constelación- que a su vez también se le han impuesto. El protagonista acaba siendo una especie de monigote tironeado desde ambas zonas de realidad. Acerca de Emar, Traverso (1999) señala que existe una angustia dada por el "hecho de concebir esa otra realidad y la incapacidad de permanecer en ella" (177). Es decir, la clarividencia del protagonista es absolutamente momentánea, y hay un desgarro producido por el no poder mantenerse en la unidad.

Al mirar hacia esta otra realidad en busca de respuestas sobre la vida humana, surgen, pues, nuevas formas de representación. En primer lugar, es necesario comprender qué es lo que encuentra el hombre en la otra realidad que luego se traduce en la conformación de figuras. El mecanismo consiste en que el hombre es atacado por las imágenes de la otra realidad, y adopta una actitud pasiva en que recibe la aparición de lo otro. Según Breton (1999), hay imágenes que se le aparecen al hombre como chispazos (344) que, en definitiva, son el resultado de la imposición de la actividad inconsciente.

Así, el protagonista de Brígida o el olvido se da cuenta de haber hecho algo mientras estaba sumido en sus divagaciones, y no sabe exactamente cuál fue la razón de su proceder: "Por esto, media hora más tarde, y sin saber cómo, me encontré sentado frente a una mujer extraña" (Del Valle, 2009: 47). Explica esta clase de eventos por una "especie de semisonambulismo" (46) producto del vivir sumergido en el recuerdo. Se entrelazan así el plano de la realidad con el de la ensoñación, dando como resultado el hecho de que el protagonista se mueva en el mundo como un sonámbulo que no tie- 
ne total dominio de sus acciones, pues está siendo constantemente atacado por las imágenes del recuerdo, que le impiden mantenerse en la realidad tangible ${ }^{1}$.

La aparición de la otra realidad se da en Juan Emar de modo similar, pues el personaje es también un receptor pasivo de imágenes que se descubren ante él. Cuentos como "El pájaro verde" o "Maldito gato" presentan situaciones en que una imagen se impone al protagonista y éste ingresa en un estado en que se vuelve presa de esa imagen. En el primer cuento, el personaje, al ver que su tío es despedazado a picotazos por un loro, no logra adoptar una actitud activa para defenderlo, puesto que está siendo a su vez víctima o paciente de una invasión de imágenes que surgen, precisamente, del ataque del ave. Emar (2006) habla exactamente de un estado de "paralización” (21). Como señala Gotschlich (1988), la actitud distanciada y contemplativa del protagonista se debe a que en ese momento está surgiendo una nueva imagen que la realidad oculta "tras su armazón formal" (103), simbolizado por el cráneo del tío José Pedro. Según Gotschlich, cada una de las respuestas de Emar a las preguntas del pájaro representa una entrega de la voluntad o confirmación del artista a la nueva realidad que se descubre ante sus ojos. Finalmente Emar acaba hipnotizado por el pájaro y se entrega completamente a la nueva realidad, ya con los sentidos anulados y en un estado de pasividad total: "Y oi que mis labios respondian: -Servid..." (23, las cursivas son mías).

En "Maldito gato" tiene lugar una invasión similar, donde Emar aparece repentinamente conformando parte de una unidad, junto a un gato y una pulga. La imagen vuelve aquí a imponerse sobre el hombre, a sacarlo de su realidad habitual para comunicarlo con una alternativa. Al igual que en "El pájaro verde", tiene lugar un vaciamiento de los sentidos para llegar a la conexión con la otra realidad. Traverso (1999) señala que hay una ruptura del continuum que da lugar a la revelación de otra realidad. Esta ruptura está dada aquí por el despertar del "ojo superior" (122), es decir, por una clarividencia que se logra tras la anulación de los sentidos.

${ }^{1}$ Llama la atención que a este sonambulismo del protagonista, que vive sumido en otra realidad, los demás personajes reaccionen muchas veces negativamente, constituyéndose como punto de contraste con esa forma de vida. Es lo que ocurre por ejemplo con Natalia Bracían, quien regaña constantemente al protagonista por no estar con sus cinco sentidos en la realidad tangible: "¿No comprende que eso es ridículo? (...) ¿Cree usted que el hombre debe pasar por la vida con la espalda cargada solamente de sueños? ¿ O le parece que la inutilidad es una virtud? (...) Pasar por la vida como una sombra atormentada (...) es sencillamente inútil y despreciable" (199). 


\section{LÍNEAS}

A continuación analizaré el uso de la línea como elemento gráfico significante en ambos autores. Las líneas son utilizadas en la configuración de las constelaciones, ya que unen los objetos del universo fragmentado en una unidad que da sentido. La línea es el elemento que permite expresar la unión de las cosas sobre la base de su existencia relativa, vale decir, promueve la articulación de "una figura que funciona como 'construcción simbólica' y que se constituye en un sistema de equilibrios" (Rubio, 2008: 12). Sin embargo, por sí sola, la línea es también portadora de significados que se relacionan con la experiencia del hombre con la otra realidad.

Un primer uso que se puede observar de este elemento gráfico se da en la representación del destino humano. En Brígida vemos la constante mención de un "hilo" del pensamiento (2009: 109, 111), o del destino humano: "el hilo que conduce estas experiencias" (64), "los hilos que mueven la existencia" (101), "el hilo de cada uno" (211). La vida aparece dibujada en términos de línea o de hilo que se enreda, tiembla, se corta, se entrelaza, etc. y es, pues, descrita con metáforas de ese orden: "No es posible vivir enredado" (211). De la misma manera, el fracaso de la existencia se grafica como una no-línea, es decir, como un punto. Como Kandinsky (1959) señala, el punto "se afirma en su sitio y no manifiesta la menor tendencia a desplazarse en dirección alguna” (30). Esta quietud expresa el estancamiento de la existencia, la inmovilidad, que es lo que ocurre con el personaje de Mónica, para quien su vida "parece contar con un punto que es a la vez partida y llegada: Luca” (236).

En la literatura de Juan Emar es posible también encontrar una recurrencia a esta imagen. En el cuento "Maldito gato", por ejemplo, se habla, respecto al encuentro del hombre con el gato y la pulga, de "las líneas por donde pasan nuestras vidas" (2006: 51). En la novela Un año encontramos expresiones como "estos hilos culebreantes que se enredan, se entretejen y no se tocan nunca" (2008: 42) para referirse al destino de Estanislao Buin, quien pasa por una calle sin saber que poco antes murió alguien en ese mismo sitio. Por otro lado, en la misma obra, el narrador cuenta que ha pasado por afuera de la casa de un conocido, pero que no ha entrado a verlo para cambiar su destino: "No ha sabido, no, que parte de su destino acaba de pasar, lentamente, junto a él, que habría bastado un paso hacia delante para hallar la ocasión casual de enderezar tantas lineas que se le han torcido en su existencia" (43, las cursivas son mías).

Pero es probablemente en "El perro amaestrado" el cuento en que se 
emplea más evidentemente la imagen de línea o de "hilo" para graficar la noción de destino. Emar y sus amigos hacen que Piticuti, el perro amaestrado, muerda a un transeúnte de cada dieciséis que cruzan por la acera. El desconocido número dieciséis, que recibirá la mordida, estimula el razonamiento del protagonista sobre el destino humano²:

¿Quién irá a ser el decimosexto? ¿Cómo irá a ser? ¿Qué ocupaciones y preocupaciones ha tenido durante el día? ¿Cuál de entre ellas lo ha empujado a entrar en la noche de las calles? (...) Viene el decimosexto. De pronto se vuelve y se aleja. No era su destino (...) Érame el total de estas andanzas una sensación ahogante de destino (2006: 76).

La potencia de este ahogo de destino lleva a Emar a darle una forma material, describiéndolo como "un monstruo hecho de hilos" (76, las cursivas son mías). Los hilos dibujan el destino de cada ser humano, a la vez que recortan el trazado urbano por el que se mueven. Por otro lado, señala el narrador que estos hilos tendían, en su mayoría, a atravesarlo por el sexo (77). De esta forma, la gráfica del destino humano obedece a la sensación de voluptuosidad descrita por Juan Emar en el momento de sentir la fuerza del destino, y lo posiciona en la ciudad, determinado por un recorrido preestablecido que manifiestan los hilos que se desprenden de su propio ser, hacia delante, y el hilo que va dejando atrás, parecido al "humor plateado de la babosa" (76). Este rastro dejado por el ser humano aparece también en Brígida, donde se nos dice: "Brígida caminaba algo desprendida del fondo y sus pasos dejaban una leve estela, una pequeña niebla, un espacio casi blanco por el que me era difícil perderla. 'Es su espacio en el mundo', pensé” (Del Valle, 2009: 24).

De esta forma, "El perro amaestrado" da cuenta del funcionamiento de la línea, que actúa como directriz del destino y a la vez constituye la fibra fundamental de la ciudad. El destino se hace sentir como voluptuosidad, y la ciudad como erotismo, todo unido por los mismos hilos irrenunciables. La vida aparece cruzada por distintas líneas que sitúan al hombre en el uni-

2 Una situación similar se lee en Brígida o el olvido, donde el sujeto, al adoptar la conducta del flaneur, se pregunta por la humanidad del transeúnte que pasa por su lado: "Si uno pudiese detenerlos uno a uno, me dije, y valiéndose de cualquier argucia, lograr que contasen su historia... penetrar en el secreto de sus existencias casi siempre temblorosas de regocijos o de lágrimas" (154) No es casual que tanto Emar como Rosamel del Valle, en tanto que quieren penetrar en esa otra realidad, manifestada por la interioridad y lo onírico, busquen dar vuelta, como calcetines, a los superficialmente vacíos transeúntes que decoran la escena del flaneur para ingresar al interior velado del ser humano. 
verso. Al centro está la experiencia erótica, el sexo que es el punto de conexión con el cosmos, donde se articula el destino humano. De esta forma, el sentimiento de lo sexual se constituye como el paso común de las líneas del destino, donde éste se hace sentir con más fuerza.

La ciudad es, pues, escenario de la experiencia erótica. Los hilos que pasan por el sexo llevan al hombre por las calles, lo mueven, y el sentimiento de angustia frente a la fuerza del destino se vuelve voluptuosidad (Emar, 2006: 76). Cecilia Rubio (2011) señala que ciudad y deseo se articulan conjuntamente, dado que "la ciudad fija y estructura lo transitorio de todo fluir del tiempo, de la misma manera que el deseo configura la existencia huidiza como una forma del destino" (256). De esta forma, se estructura un 'trayecto del deseo' que, de acuerdo con la autora, une las categorías de mujer, azar y destino: "Las mujeres suelen ser agentes del conocimiento del mundo, porque muchas veces ellas encarnan una forma del destino" (252).

Este es el tipo de relación que se encuentra en "Chuchezuma" (Emar, 2006), donde el recorrido urbano despierta el sentimiento sexual en el caminante. Cecilia Rubio se refiere aquí también al vínculo entre la ciudad y la voluptuosidad, el cual se sustenta en el tránsito, en el movimiento. La autora apoya esta convicción recurriendo al cuento "Pibesa" (Emar 2006), donde se lee: "Siempre tiembla Pibesa cuando le propongo ir a alguna parte. Ir. En el verbo ir, Pibesa ha concentrado todas sus voluptuosidades. No importa adonde sea. Es el hecho de ir y ello le basta" (2006: 132). A través del movimiento, señala Rubio (2011), "el sujeto transforma el dédalo de calles, signo del irreconocimiento y la desapropiación, en un trayecto del deseo. Recorrer la ciudad es crearla a la medida de lo que dicta, si es que todavía se deja oír, el deseo" (259).

En "Chuchezuma", el ir por la ciudad -vale decir, el flujo del destinolleva al protagonista a experimentar una sensación de voluptuosidad, traducida luego como una "irresponsabilidad" (114). En suma, el destino se siente en una descarga de vértigo. No sería del todo caballuno, por otra parte, decir que Chuchezuma es la encarnación de una línea de destino. Su descripción física y su continuo movimiento así lo sugieren: "Al hallarme frente a su puerta, pasó una mujer. Silueta fina, de andar suelto (...). Pasó rápida. La seguî" (112). A este respecto resulta iluminadora una descripción teórica de la línea: "Es la traza que deja el punto al moverse y es por lo tanto su producto. Surge del movimiento, al destruirse el reposo total del punto" (Kandinsky, 1959: 57) La línea es, así, expresión de movimiento, por lo cual el mero hecho de que Chuchezuma se mueva proporciona un argumento para entender a este personaje como manifestación de una función 
lineal, idea que se ratifica si, además, se tienen en cuenta aspectos como su delgadez física y la resonancia de "El perro amaestrado" con las líneas que guían -como Chuchezuma- al hombre en la ciudad-destino. El hombre, cuyo destino es graficado en líneas que lo mueven, aparece, en "Chuchezuma”, llevado a través de la ciudad por los movimientos de la mujer, que, de acuerdo con las palabras de Rubio citadas más arriba, es encarnación de esta línea de destino.

En "Pibesa" el caminar se desarrolla, también, sobre un juego de deseo en el cual, al comenzar a andar Pibesa, se produce en el hombre "una excitación desenfrenada" (133). Es interesante observar que nuevamente la mujer tiene "un talle espigado" (132), y que Emar recurre a las líneas para explicar el paso de los dos personajes: "cuando un puntapié mío lanzaba el papel de rosa de modo a dejarlo en su línea de marcha, ella lo golpeaba y lo enviaba a mi línea" (132). De esta forma, nuevamente la mujer y el caminar promueven la aparición de líneas que grafican el destino de cada uno y que constituyen también la experiencia de lo sexual.

Respecto a este punto, puede decirse que Brígida en la novela de Rosamel del Valle puede ser vista en términos semejantes. El protagonista constantemente la percibe entre la multitud y comienza a seguirla. En ese sentido, la mujer dibuja el recorrido del hombre en la ciudad, pues guía los pasos que da el protagonista en su sonambulismo. En otras palabras, dibuja la línea de su destino. Se constituye así Brígida como la mujer guía, propia del surrealismo, que transporta al hombre a las zonas ocultas de la realidad, pues lleva al protagonista a un estado de hipnosis en que acaba siguiéndola sin preocuparse del mundo que lo circunda ${ }^{3}$. Podemos comprenderla, pues, como encarnación de una línea de destino en la medida que consideremos -al igual que con Chuchezuma- su movimiento fugaz y el rol de guía que

${ }^{3}$ La mujer del surrealismo es configurada en función del hombre, a quien transporta a las regiones de lo irracional y lo oculto. Sanhueza (2009) señala que un rasgo fundamental del surrealismo es "su reinterpretación del mito del eterno femenino. Las mujeres desempeñan allí el papel de espejo de la verdad (...), poseen un siquismo excepcional, son guardianas de una realidad mítica" (21). Daniela Wirth (2010), por su parte, expresa que "la mujer del surrealismo es la mujer hada, la musa inspiradora que debido a su irracionalidad puede liberar al hombre de sus ataduras con lo racional y material para conducirlo a las altas esferas de la espiritualidad y la libertad de sí mismo" (38). Acerca de Brígida, señala Wirth que "A nivel arquetípico, Brígida es noche, es decir, oscuridad e inconsciente, lo que está oculto y es potencialmente peligroso" (60). En Emar y Rosamel es posible ver que, además, la mujer se relaciona frecuentemente con la muerte. Es lo que ocurre por ejemplo con Camila en "El unicornio" de Emar. También puede verse en "Chuchezuma", donde se vincula a la mujer con la sangre y lo vampiresco, la muerte en términos acaso más vitalistas. En Rosamel basta recordar la imagen de "la mujer muerta en una vitrina" (37), la muerte final de Natalia, lo que sucede en momentos que el protagonista cree que la prostituta ha muerto: "Mónica muerta" (89) También está la mujer agónica, es decir, la joven enferma, que en su viaje va hacia la muerte-olvido. 
asume al trazar el camino del protagonista:

Y Brígida caminaba a lo lejos. ¿Hacia dónde? Su cuerpo solía perderse entre otros cuerpos, hasta confundirse un poco con la multitud (...). Su espalda era una pequeña luz fugitiva. Yo seguía esa luz. (...). Mi ser entero solo sabía una cosa: que no lejos de él iba Brígida Helmes, sola en la noche. Es decir, mi propio destino (248).

De esta forma, Brígida misma es el destino del protagonista, y el destino, o fin de la vida, está dibujado en la novela en términos de línea. Sin embargo, no contamos con una descripción física de Brígida que baste para decir que evoca desde la forma a una línea. Como dice Wirth (2010): "Brígida tiene nombre, pero no verdadera sustancia. El protagonista la presenta como a una imagen o un espectro, sin bordes ni contexto alguno, es una mujer que de cierta forma no necesita más que su nombre (...) para ser una realidad" (59). Así pues, en tanto línea de destino, es la mujer quien guía al hombre y lo envuelve en un estado de ensoñación o de vértigo, con lo cual logra conectarlo con otras realidades.

Por otro lado, en concordancia con esta representación de la vida en base a "hilos" o "líneas", aparece en Brígida o el olvido un personaje muy significativo que se opone a la forma de vida del narrador, cuya vida se constituye como una eterna fuga -el recuerdo-desde la línea central -el mundo real- ${ }^{4}$. Este personaje es el funcionario don Dionisio Merales Alzúa, quien, durante la cena en casa de la viuda Irene Baldunza", expone que "el hombre tiene una línea a seguir" (Del Valle, 2009: 137). Es decir, limita la vida humana a una linealidad unidireccional sin posibilidades de fuga. Sin embargo, es un personaje altamente patético, cuya vida no tiene ninguna trascendencia, y que despierta la antipatía del protagonista y sus amigos. “¿Qué asco!” (138), dice Natalia. En suma, Dionisio Merales Alzúa, con su estilo de vida "lineal”, es encarnación de la aborrecible realidad burguesa que Rosamel continuamente busca evadir. Por supuesto, también es imposible que una línea como la que propone el funcionario constituya constelación, pues es necesaria la uti-

\footnotetext{
${ }^{4}$ Resuenan aquí las palabras de Emar en Umbral: "Tendré que hacer un verdadero esfuerzo para mantenerme ahora sobre una misma línea, una línea recta en lo posible, recta cuanto se pueda a lo largo de este relato. Verdadero esfuerzo para no escaparme a derecha o izquierda. Porque la esencia misma del relato es la escapada permanente hacia todos lados" (Emar, 1996: 1130, citado en Rubio, 2008: 18).

${ }^{5}$ Este pasaje es uno de los pocos en que se permanece largo rato en el mundo real. ¿¿La intención? Evidenciar la intrascendencia de mantenerse en ese mundo y burlarse de la miseria de los personajes burgueses.
} 
lización de la línea en la unión de elementos, o su disposición como "objeto en sí" para dar cabida a una experiencia intersticial. La función de la línea de Dionisio es solo una prescripción. Se articula como limitante del actuar humano, que condena la vida a una sola línea sin posibilidad de fuga ni permite el surgimiento de una figura, dado su carácter único ${ }^{6}$. Por ello, Dionisio cierra la posibilidad de encontrar, en la constelación, la otra realidad.

Inmediatamente podemos comparar este personaje con el tío José Pedro, del cuento "El Pájaro verde" de Emar. Este sujeto es también representación de la burguesía y de las convenciones del realismo odiado por Emar. Encarna, pues, todo un paradigma artístico al que se oponen las nuevas formas de arte. Es significativo que tras la destrucción de su cráneo, se imponga una línea de fuga constituida por el "hilo escarlata" (2006: 22) que brota de su interior. El hilo o línea -que ahora es un objeto en sí, no un esquema prescriptivo- constituye revelación artística, puesto que, como señala Guillermo Gotschlich (1988), es en el destrozo del cráneo del tío que se descubre una nueva forma de arte. La destrucción física deviene ruptura respecto a las prescripciones del ajado realismo, y permite encontrar una nueva belleza, representada en el fino hilo de sangre y en la redondez del ojo arrancado como con "una cucharilla especial" (Emar, 2006: 22).

\section{CONSTELACIONES}

En la constelación se unen los diversos elementos de la realidad, pues las líneas de destino se entrecruzan, se proyectan de un elemento a otro, de modo que se origina una figura que da un sentido de unidad a los elementos.

Por una parte, en la novela de Rosamel del Valle se aprecia un afán de totalidad en la explicación por medio de triángulos de las tres mujeres más importantes en la vida del protagonista, es decir, la joven enferma, Brígida y Natalia:

[De la joven enferma] a Brígida no existía más que un paso. Pero donde todo se levantaba ya como una cosa desesperada era en Natalia. Este triángulo me conducía con tanto rigor y encantamiento como el triángulo

\footnotetext{
${ }^{6}$ Como señala Emar en "Maldito gato", la línea única no sirve para nada: "Pues al fin y al cabo, un rayo, uno solo, como lo digo, 'uno', es una unidad y hasta ahora, que yo sepa, en la unidad uno, no ha sido posible realizar expresión alguna de vida manifestada” (2006: 49). Sin embargo, hemos visto que en repetidas oportunidades la línea adquiere un gran valor expresivo en las representaciones de la realidad otra.
} 
religioso de la Trinidad conduce y reduce al creyente profundo. Toda mi voluntad desaparecía allí (...). Y después Natalia (...): 'la tercera línea de un triángulo', del triángulo cuyo punto de partida, ya lo he dicho, era la joven enferma” (2009: 189-190).

Es evidente, pues, el poder totalizante que se atribuye a la figura, pues permite reunir en una sola imagen el potencial de las tres mujeres. Fundamentalmente, el amor, como uno de los temas centrales de la novela, se expresa en la figura por medio de la totalidad de las mujeres, que constituyen una fuerza mayor. Cuando se ha trazado la tercera línea, se cierra la figura y se consigue una unidad autosuficiente. Así, son las tres mujeres principales las que, en su ordenamiento triangular, logran expresar con la fuerza necesaria la idea del amor. Por otra parte, la misma tendencia triangular se observa en el personaje de Cristina, quien, para dar una explicación a su confusión amorosa entre su padre y Felipe, recurre a la conformación de una figura en la que el centro es ella misma: "Mi padre estaba encima de mí, y su amor me seguía los pasos, pero era otro amor, por supuesto. Sin embargo, Felipe y él se unían, se ligaban a veces. Y cuánto esfuerzo hice para reunir palabras y decírselo a Felipe. Para hablarle de esa doble imagen" (215). La tensión Felipe-padre que tiene lugar en Cristina promueve la apertura de una nueva figura, de la cual Cristina es el eje central. La conformación de un triángulo que agrupa los diversos objetos del amor en una sola imagen le permite a Cristina encontrar el erotismo en su realización plena y con un sentido total'.

En Juan Emar podemos encontrar la conformación de figuras como motivo de su obra en general. Como señala Rubio (2005) acerca de la estructura de Diez, "la construcción simbólica [se convierte] en un mecanismo que (...) se presenta en todos los cuentos como representación de la euritmia poética con la que se configura Diez" (155). Así, la configuración numérica del libro proporciona una clave de lectura que permite abarcar cada cuento

${ }^{7}$ Asimismo, llama la atención el hecho de que la experiencia erótica constituye un anclaje con otra realidad. No es solo la mujer quien lleva al hombre a las zonas ocultas, sino que, como vemos en la relación entre Cristina y su padre, el hombre también puede hacerlo. En este caso, la experiencia erótica se da por un sentimiento de amor respecto al padre. El hombre, pues, es la imagen del creador que insufla sobre su criatura un nuevo sentir que la vincula con una realidad diferente: "Y sobre todo cuando él está a mi lado es cuando puedo decir que el mundo se abre ante mí en toda su inmensidad e intensidad (...). Lo veo y todo lo que debe decirme sale desde ese mismo instante de su boca y entra en lo más profundo de mi alma, como si yo (...) no hubiera sido momentos antes sino una estatua" (Del Valle, 2009: 109). Se observa, pues, que para Cristina el padre constituye una imagen que, desde una especie de erotismo demiúrgico, le otorga una capacidad de percibir el mundo en su totalidad, como una superrealidad. 
como parte constitutiva de un todo, de una unidad de sentido expresada en la matriz numérica del diez como símbolo de la Unidad (153).

Emar tiene conciencia de que los elementos de la realidad constituyen una unidad, de modo que expresa dicho vínculo mediante figuras que los agrupan. Al respecto, Soledad Traverso (1999) explica que, producto de su facultad clarividente, Juan Emar logra ver el todo, mientras que los demás permanecen en el fragmento, sin tomar conciencia de su unidad (138). Tal como afirma Lizama (2001), la escritura emariana busca aprehender la totalidad del universo, que es una "compleja red de relaciones entre las diferentes partes de un conjunto unificado" (29):

El mundo se concibe como una unidad indivisible y dinámica cuyos elementos están estrechamente vinculados y pueden comprenderse sólo como modelos de un proceso cósmico. De esta forma, los componentes del universo (...) no son "cosas" sino correlaciones de cosas (2001: 29).

Esto se observa claramente en el episodio del barrigón de la novela Ayer, donde cada objeto tiene su razón de ser en la medida que está conectado a otro, en relación con otro: el panzón al aire, el aire a los muros, los muros al edificio, la Tierra al sol, etc. (1998: 52).

Ahora bien, este análisis se centrará en la construcción de dos constelaciones particulares. Por un lado, la conformada por la joven enferma, la tía y el protagonista en Brígida. Por otro, el triángulo compuesto por un gato, una pulga y el personaje autodiegético en "Maldito gato" de Emar. La importancia de éstas radica en que ambas constituyen un recurso por medio del cual el hombre logra conectarse con una realidad distinta de la tangible. Es fundamental para este análisis comprender primero que en ambos autores se encuentra una concepción de la vida en términos de un permanente estado de angustia. En Emar, como ya hemos señalado de acuerdo a Traverso (1999), existe un dolor por no poder permanecer en la otra realidad. A la vez, como hemos visto, el destino despierta esos sentimientos en el protagonista. En "El perro amaestrado", por ejemplo, es posible observar que la sensación de destino se une con una angustia que, a su vez, se compenetra con la voluptuosidad (Emar, 2006: 76).

En Brigida o el olvido, por otra parte, podemos observar que el personaje lleva también una vida marcada por el sentimiento de angustia: "Pero ahí está la angustia (...) La felicidad reside a la larga en la más terrible de las esperas" (Del Valle, 2009: 149). Esta terrible espera se da por la entrevisión de la otra realidad en el mundo onírico y el recuerdo con su contrapar- 
te, el olvido, encarnado en Brígida. La vida del protagonista está dada por seguir a esta mujer-idea inalcanzable. Sobre todo por su fugacidad, podemos decir que Brígida es representación ella misma de un intersticio, pues el protagonista logra entreverla por instantes en medio de la multitud. La angustia surge de no poder llegar a ella, de estar siempre en una continua persecución: “ $\mathrm{OH}$, el tiempo que me estuve allí, como sujetándola desde lejos! (...). Nunca me pareció más horrible la dicha. Porque evidentemente en esa imagen estaba mi dicha" (248). Su esencia intersticial radica en que la vida aquí es percibida como un continuum sin sentido y movedizo, de cuya ruptura aparece Brígida, que se convierte en la razón de ser del protagonista. Según él, la vida no es sino un confuso rumor: "Personas, máscaras, sucesos, cosas... ¿Qué significado tiene todo ello cuando uno pasa entre ellas como un fantasma?" (243). Al ver a Brígida dentro del turbulento devenir de la vida, el protagonista encuentra esa otra realidad que se da por la detención del continuum, pero su tragedia consiste en no poder alcanzarla. Es, en definitiva, la misma angustia emariana de percibir la otra realidad y no poder permanecer en ella. Es la angustia de vivir persiguiendo a Brígida, que se traduce en una dicha horrible ${ }^{8}$.

La concepción de la vida desde la angustia nos permite comprender la fragilidad del encuentro con la otra realidad, puesto que dicha realidad se articula sobre un equilibrio muy delicado de las partes en la figura. El riesgo de que la constelación se rompa y se vuelva a la realidad está siempre latente. La noción de equilibrio es, pues, fundamental en la constelación, y en ello se explica su fragilidad.

El equilibrio de la figura se fundamenta, en Emar, en la concepción del universo como un tejido de relaciones entre las cosas. Cecilia Rubio (2008) explica el mecanismo de construcción de la figura sobre la base de un equilibrio entre las partes:

[E]n el mundo las cosas se equilibran entre sí de manera (relativamente) estable, de allí que haya que considerarlas en su unidad como una configu-

\footnotetext{
${ }^{8}$ Además, en la obra de Rosamel del Valle (2009) podemos encontrar diversas construcciones en las que se reúnen términos opuestos o se expresa una tensión entre contrarios para representar la angustia. Hay algunos ejemplos que pueden ayudar a comprender lo que intento decir. Helos aquí: "Enrédame a otra claridad o a otra tiniebla" (201), "su propia dicha o angustia" (211), "la vida y la muerte vivían en él como el verano o el invierno" (251), "En cada minuto hay una especie de presencia, real o no, que apaga o enciende las luces y que estalla, lejos o cerca" (39, las cursivas son mías). Se nota en estos ejemplos una doble tendencia hacia ambos opuestos articulados en tensiones. En la novela, a modo global, pueden apreciarse otros ejemplos, tales como las tensiones entre memoria y olvido, mundo interior y mundo exterior, pasado y presente, vejez y juventud.
} 
ración: el uno es siempre dos que están en tensión. Esta tensión confiere a la figura un movimiento vital, el de circulación (...) de este modo, la figura se transforma en un pequeño organismo que se estructura con estos dos puntos interconectados en el tiempo y en el espacio (2008: 14).

La figura emariana tiene su cierre en la incorporación de un tercer elemento que permite sostener la tensión establecida entre los dos primeros. Emar avanza "desde la dualidad a la trinidad, lo que equivale a avanzar en el plano geométrico desde el paralelo o desde el ángulo al triángulo, al establecer los requisitos del equilibrio como la formación de una figura compuesta por tres entidades" (Rubio, 2008: 17).

Esta noción de equilibrio puede verse, por ejemplo, en "El Hotel Mac Quice”, donde se articula un triángulo formado por la brújula -posición del protagonista-, las estrellas y el hombre al que el personaje va siguiendo: "Mis ojos iban del hombre a las estrellas, de las estrellas a la brújula, de la brújula al hombre" (Emar, 2006: 151) El equilibrio de la figura radica en el hecho de que en los dos ángulos inferiores del triángulo hay un hombre, de lo cual puede deducirse que ambos no son sino el mismo hombre, reflejado a ambos lados del triángulo, dada la simetría que tiene la figura.

Sin embargo, es en la constelación de "Maldito gato" donde la noción de equilibrio queda de manifiesto explícitamente: "No había duda, ni la menor duda, que al juntarnos así los tres, habíamos formado una figura, (...) habíamos realizado un equilibrio, un perfecto equilibrio entre fuerzas aisladas" (Emar, 2006: 52). Este equilibrio se logra por una nivelación de los tres seres en fuerzas equivalentes, es decir, en un gato cada uno: "sumados como poder de acción y divididos por tres, damos la potencia activa de tres gatos en medio del universo (...) [pero] no hay que considerarlos en su calidad de tales, sino en su calidad de fuerzas constitutivas y sobre todo en su calidad de elementos" (54).

Por otro lado, en Brígida o el olvido la constelación presente en el recuerdo del protagonista, y que está constituida por él, la joven enferma y su tía, está también construida sobre la base de un equilibrio entre las partes. En primer lugar, debemos observar que hay una tensión sobre la que se balancea la figura, que es la oposición entre la joven enferma y la tía vieja, es decir, una tensión entre juventud y vejez que se proyecta hacia el protagonista, sentado frente a las dos mujeres. El hombre actuaría como el eje sobre el que se sostiene esta tensión.

Por otro lado, hay una noción de destino que es parte esencial de la constelación. Como vimos anteriormente, el destino del hombre aparecía 
descrito en términos de líneas. La constelación, puede decirse, está dada por el momento en que confluyen los destinos -líneas- de los distintos elementos. El extracto de la novela Un año de Emar (2008) que he citado más arriba, donde se habla de las líneas que no se cruzan, muestra cómo los elementos se pierden solos, como cometas salidos de su órbita, sin llegar a unirse a los otros. El destino de un hombre solo que resbala por el lado de los otros destinos no tiene razón de ser, mientras que la unión de los hilos de dos o más vidas permite la conformación de una figura, es decir, una unidad mayor que sintetiza los fragmentos.

La noción de destino es evidente en la constelación de Brígida o el olvido, donde se señala que no es una casualidad la unión del protagonista con la joven enferma y la tía de ésta en el coche que va a Santiago: "mi existencia se había unido definitivamente a esos admirables seres entre quienes veía que mi destino se disponía ya a ocupar un sitio seguro" (Del Valle, 2009: 206). Las tres vidas aparecen unidas en un mismo tiempo y en función de una misma búsqueda, la búsqueda de la felicidad: "Y los tres éramos infelices. La joven por su mal, la señora por su existencia y yo por el grito todavía próximo de mi padre que se negaba a quedarse solo, aun bajo su propia tierra" (121). La infelicidad común constituye la razón de ser de la constelación. En su unión, los tres personajes logran un escape de su triste existencia, puesto que "hay también un día radiante hasta en el ser más infeliz. Y aquél era nuestro día. El día de la enferma, de la tía y el mío" (121). De esta forma, los tres destinos quedan ligados en ese espacio cerrado en que tiene lugar un instante de felicidad en las grises existencias de los personajes. En ese sentido, se expresa también una detención del continuum, puesto que las vidas de los tres se detienen en ese punto y se conectan entre sí en un momento de plenitud.

En "Maldito gato", por otra parte, tiene lugar un choque de tres destinos en que cada uno deja de ser una fuerza individual y solitaria para pasar a formar parte de la figura: "mi signo cambiaba, mi signo hombre se iba, mi signo era otro al pasar a ser elemento" (Emar, 2006: 56). Cada uno de los elementos ha sido arrancado de su existencia particular para constituirse como elemento de una unidad mayor. Este dejar de ser se expresa como un abandono del mundo para adquirir un nuevo destino. Para Emar es un adiós a su vida de hombre en tanto ser independiente, que él relaciona con una imagen reiterada en su mente, la de una grúa que lo saca del mundo (58). Así, el destino de cada uno, del hombre, del gato y de la pulga, queda unido al de los otros dos y se separa de su anterior significado, el de "algo suelto, volante, inocupado" (58), para pasar a ser en relación a los demás en la nueva figura. 
El universo entero se ha detenido en el momento en que la línea del destino del protagonista intersecta con las de sus compañeros en el embudo (55-56). Luego de este instante de paralización cósmica, sigue un "vaivén universal" (65) tras el cual todo se reacomoda según un nuevo orden. De esta forma, la constelación se mantiene en un estado de suspensión propio de toda experiencia intersticial, según hemos dicho más arriba de acuerdo a los planteamientos de Mac-Millan (2005). La quietud de la figura garantiza una permanencia en el intersticio, por lo cual el gato, la pulga y el hombre deben mantener su posición como elementos constitutivos, a fin de no perder de vista la otra realidad que en su constelación logran atisbar.

La vida de cada entidad se trasciende, pues, en la constelación y se amalgama con la de los otros en el total de la figura. En este sentido, la vida en ambos autores puede comprenderse como una constante búsqueda de la constelación. La línea de cada uno se desenvuelve por separado, hasta el momento en que se topa con las líneas de otros elementos que le son complementarios. Es el instante de formación de la figura. De esta manera, Rosamel del Valle menciona que "en los destinos hay siempre un eslabón perdido" (2009: 225), es decir, hay una conciencia de que cada elemento -suelto, solitario, inconcluso- necesita ser complementado por otro $\mathrm{u}$ otros que desenvuelven, por su parte, su hilo independientemente. $\mathrm{Y}$ ese complemento es el que se encuentra en la constelación, pues, como hemos visto en la tríada hombre-joven enferma-tía, la vejez se complementa con la juventud, la madre con los hijos, el hombre con la mujer, etc. De esta forma, se expresa la vida como una constante búsqueda de los elementos necesarios para producir la unidad de la constelación.

Por otro lado, como hemos visto en "Maldito gato", también hay una concepción de la vida en base a esta búsqueda de los elementos de la constelación. Para Emar, todo había ido suelto por el mundo, sin un sentido determinado, hasta el instante en que las tres fuerzas pasaron a constituir una figura: "Hasta entonces nosotros y las fuerzas que éramos, habíamos, como todo lo restante, rodado y rodado, con más o menos golpes y sinsabores" (2006: 63) La conformación de una figura es el fin último de cada vida, el puerto al que llegan los destinos sueltos de cada elemento, para entonces encontrarse con los otros y alcanzar un estado de plenitud expresado en un intersticio que se desea mantener en el tiempo:

Todo vuelve para todos a tomar su ritmo acostumbrado y yo, en mi plena estabilidad, noto que las horas me son ligeras. Yo, él, ella... Ella, yo, él... Él, ella, yo... Esto me ocupa, me absorbe. Pasan las horas. Pasan los días. 
Mi vida entera anterior la siento definitivamente desaparecida (...). Pasaron años. Nuestras vidas estaban reducidas al mínimo de movimiento (2006: 66).

En la novela de Rosamel del Valle la constelación permite establecer también una conexión con la realidad otra. Esa otra realidad está dada por el recuerdo, que constituye la vía de escape del protagonista, y es fijado en la memoria por medio de la creación de una figura. El sentido de la unión está directamente relacionado con la circunstancia del viaje hacia la capital, en cuyo punto de partida tuvo lugar la muerte del padre del protagonista y, se puede presumir, en cuyo destino ocurrirá la muerte de la joven enferma. En la nomenclatura de Rosamel del Valle, la muerte es el olvido (2009: 115), de manera que el viaje establece una suspensión, una pausa entre un olvido y otro, una muerte y otra. La constelación detiene el proceso, pone un freno al desbocado devenir de la vida hacia la muerte. Al igual que en "Maldito gato", tiene lugar una detención del mundo que los rodea, y solo queda la constelación como única verdad del universo, como la Unidad donde el destino humano alcanza su plena realización: “¿Qué dulce es el mundo cuando se detiene! (...) Porque, en verdad, el mundo estaba detenido" (157). Las tres vidas se mantienen así suspendidas en el espacio del coche. De esta forma, la figura que conforman la tía, su sobrina y el protagonista es un intento por mantener esa detención. Es un intento de resistir al olvido.

El temor de los personajes radica en su separación al llegar a destino, que traerá como consecuencia el olvido mutuo. En ese momento, la constelación llega a su clímax, a su punto más elevado de resistencia y unión: los tres personajes se toman de las manos: "En aquel momento me hubiera echado a llorar. Imposible transcribir mi estado de ánimo, la congoja de mis veinte años, la esperanza creciente como un rayo a la vez dulce y aniquilador. Bajé la vista y besé casi desesperadamente aquellas manos, ya tan amadas para mí" (188). Esta ligadura física entre los elementos del triángulo constituye el último y desesperado intento por evitar la separación, por mantener el estado de plenitud y felicidad que han creado al interior del coche. En este punto los personajes se reconocen como verdaderamente unidos a los otros, saben que sus existencias han alcanzado un estado de plenitud, y la posibilidad de perderlo los incita a reforzar su unidad.

Sin embargo, la ruptura de la constelación es inevitable cuando llegan a Santiago. La unidad no se puede mantener, y el desgarro que ocasiona en los personajes esa imposibilidad es evidente. El instante de la separación supone además una derrota frente al olvido o su materialidad, la muerte. Como he- 
mos señalado, la constelación formada en el coche constituye una resistencia a esa posibilidad. La muerte de la joven es algo que desconocemos, pero que sin embargo no deja de ser un peligro latente, de manera que no es descabellado sugerir que se ha mantenido viva durante la constelación, gracias a la energía que ha adquirido en el estado de plenitud, pero que morirá al hallarse fuera, como objeto independiente sin una figura que le de sentido. De hecho, el adiós de los personajes al llegar a destino es comparado con la muerte del padre del protagonista: "Me despedí de ellas del mismo modo que me había despedido de mi padre el día anterior, como quien dice adiós a algo más que a las sombras, a algo más que a lo que se acaba de descubrir y perder" (210).

Por otra parte, la ruptura inminente de la constelación, cuando ya se acercan a Santiago, se expresa con metáforas que sugieren el trágico triunfo de la mediocridad cotidiana y del olvido sobre el estado de plenitud y la posible felicidad que lograron entrever los personajes durante el viaje. Por un lado, "el sol se había perdido de pronto y empezó a nublarse" (206). El sol actúa, respecto a la constelación, como el símbolo de su plenitud y suficiencia, e ilumina la existencia de cada uno de ellos durante el recorrido: "El sol asomaba, a veces, la cabeza por la ventanilla" (157). Representa la plenitud, la felicidad alcanzada por los tres personajes en la constelación. Por tanto, su desaparición significa la extinción de la luz en las vidas de los tres personajes, el apagarse paulatino de la posibilidad de ser felices. A la vez, la desaparición del sol representa la inminencia del olvido. La vida se ha nublado, los personajes volverán a ser destinos sueltos y tristes, se olvidarán unos de otros y cargarán con la terrible condena de haber constituido una unidad y no haber logrado perpetuarla.

También los caseríos que divisan al acercarse a la capital son símbolo de la mediocre vida burguesa a la que quedan condenados: "un grupo de casas horriblemente pintadas a listas blancas y rojas y ya tan sucias que era fácil pensar en una pequeña aldea de cartón, abandonada y llovida” (207). Esta desagradable visión es lo que los vuelve al mundo real, a la vida sin rumbo y a la infelicidad común que habían logrado extinguir en la unión de sus destinos. Cabe pensar aquí en la tensión campo-ciudad que se expresa correspondientemente con el momento de plenitud y la condena final de la separación. En efecto, la constelación está marcada por un vínculo con la naturaleza que los rodea durante el viaje: "la naturaleza se hacía transparente y mucho más grandiosa en su reposo" (157). De esta forma, el golpe de realidad que los aterriza y separa está aún más acentuado por el contraste entre la naturaleza idealizada y una ciudad ruinosa y desagradable. 
La constelación de "Maldito gato" permite la apertura de un intersticio que conecta al hombre con la otra realidad y lo lleva a un estado de plenitud. En Brígida el triángulo del coche es una forma de resistir al olvido, pues la potencia expresiva de la triple imagen fija el recuerdo. Esta constelación está articulada ya en la realidad otra -la del recuerdo-, y sirve para mantenerla en el tiempo. A la vez, conecta a los personajes con un estado de plenitud y felicidad. En ambas constelaciones, sin embargo, el recuerdo es un componente esencial. Emar plantea que, en caso de desarmar el triángulo que conforma con el gato y la pulga, quedaría el recuerdo de ese instante. Él, como fuerza sola, tendría una nueva visión de la vida: "Tendencia a volver a encarnarse, a no más seguir circulando" (2006: 70). De esta manera, el recuerdo de la unidad lo impulsa a buscar esa plenitud perdida. La reacción del protagonista de Brígida a esta situación es refugiarse en el recuerdo de la unidad, volver una y otra vez a ese momento perdido. La realidad otra está en el recuerdo, y se mantiene por medio de la figura. Así, en Rosamel la memoria actúa como el lugar en que se reproduce el instante de la constelación.

En suma, el equilibrio de las constelaciones expresa una réplica del equilibrio en que se basa el universo. Juan Emar en "Maldito gato" explicita este punto: "allí en el embudo se reflejaba otro, el Todo. Pero no solo se reflejaba, también se reproducía" (55). La energía del cosmos circula por la figura, de un elemento a otro, reproduciendo un equilibrio mayor que aúna a todos los elementos del universo: "No sólo se trata de construir una figura donde las fuerzas se equilibren, sino de que dicha figura encierre en sí una forma de existencia que pueda constituirse en paralelo del cosmos, es decir, que sea ella misma unidad y totalidad" (Rubio, 2008: 17). La constelación une, así, los elementos de una realidad que se percibe fragmentada. Como dice Hatzfeld (1951), "el dilema psíquico de la desintegración moderna lleva al descubrimiento de formas geométricas y esenciales" (14). En la simpleza y complejidad de la figura se encuentra un total que agrupa los diversos elementos que están inconexos en el mundo. El ser humano busca un principio cohesivo sobre el que se ordenen todos los pedazos de una existencia que, como dice uno de los vagabundos de Brígida o el olvido, "está hecha a trozos" (251).

\section{REFERENCIAS}

Breton, André. (1999). Primer Manifiesto del Surrealismo. En De Micheli, Mario. Las vanguardias artísticas del siglo XX. Madrid: Alianza. 
Cirlot, Juan Eduardo. (1953). Introducción al surrealismo. Madrid: Revista de Occidente.

Del Valle, Rosamel. (2009). Brígida o el olvido. Santiago, Chile: Cuarto Propio.

Emar, Juan. (1996). Umbral. Santiago de Chile: Biblioteca Nacional. . (1998). Ayer. Santiago de Chile: Lom.

. (2006). Diez. Santiago de Chile: Tajamar.

(2008). Un año. Santiago de Chile: Tajamar.

Gotschlich, Guillermo. (1988). El Pájaro Verde: proposición de una poética. Revista Chilena de Literatura, 32, 91-107.

Hatzfeld, Helmut. (1951). Superrealismo. Buenos Aires: Argos.

Kandinsky, Wassily. (1959). El punto y la línea sobre el plano. Buenos Aires: Nueva Visión.

Lizama, Patricio. (2001). Emar y el deseo de otra esencia para la vida. Paréntesis, 8, 25-33.

Mac-Millan, Mary. (2005). El intersticio como fundamento poético en la obra de Julio Cortázar. Frankfurt: Peter Lang.

Rubio, Cecilia. (2005). Diez de Juan Emar y la tétrada pitagórica: iniciación al simbolismo hermético. Taller de Letras, 36, 149-165.

. (2008). La euritmia de Juan Emar: Teoría del equilibrio y sistema constructivo. Acta Literaria, 37, 9-23.

(2011). Ciudad burguesa y trayectos del deseo en la escritura de Juan Emar. En María Nieves Alonso y Carmen Alemany (eds.), Diálogos para el bicentenario (pp. 243-261). Concepción: Editorial Universidad de Concepción.

Sanhueza, Leonardo. (2009). Reencuentro con el sonámbulo. En Rosamel del Valle, Brígida o el olvido (pp. 17-32). Santiago, Chile: Cuarto Propio.

Traverso, Soledad. (1999). Juan Emar: La angustia de vivir con el dedo de Dios en la nuca. Santiago, Chile: Ril.

Wirth, Daniela. (2010). La búsqueda del Yo. Rosamel del Valle y el Surrealismo. Tesis para optar al grado de Magíster en Letras, mención Literatura por la Pontificia Universidad Católica de Chile.

Yurkievich, Saúl. (1984). A través de la trama: Sobre vanguardias literarias y otras concomitancias. Barcelona: Muchnik. 